\title{
Os dois olhos do dragão: o impacto da tradução de Beowulf por J.R.R Tolkien no Polissistema Literário
}

\author{
Carolina Alves Magaldi* \\ Isabella Aparecida Nogueira Leite** \\ Mariana Mello Alves de Souza**
}

\begin{abstract}
RESUMO: Neste artigo iremos questionar como a tradução de J.R.R. Tolkien da obra Beowulf pode ter impactado a dispersão da literatura em inglês antigo nos dias atuais e também como tal obra de ficção pode ser usada no meio acadêmico de estudos em literatura inglesa. Dessa forma, nos dedicaremos a esmiuçar o papel desempenhado por tal tradução na divulgação acadêmica e literária da literatura em inglês antigo nos séculos XX e XXI, bem como na formação de uma identidade inglesa cultural e literária (VENUTI, 2002 [1998]), na medida em que se converteu em um bem simbólico e uma ferramenta cultural (EVEN-ZOHAR, 2010).
\end{abstract}

Palavras-chave: Tolkien; literatura inglesa; tradução; ensino de literatura.

\section{Introdução}

Este artigo propõe-se a discutir o poema anglo-saxão Beowulf, que data do século VIII d.C., e sua tradução para o idioma inglês feita por J.R.R. Tolkien (1892-1973) a partir de uma perspectiva literária, cultural e didática. Com isso, se buscará questionar como a tradução de Tolkien pode ter impactado a dispersão da literatura em inglês antigo nos dias atuais e também como obras de ficção como Beowulf podem ser usadas como textos introdutórios para estudantes acadêmicos que buscam se especializar em literatura inglesa.

Para isso, dividiu-se o artigo em quatro partes: a primeira será composta por uma pequena introdução ao trabalho de J.R.R. Tolkien, filólogo e linguista da Universidade de Oxford, abordando sua biografia, pessoal e acadêmica, sua relação com o inglês antigo e as literaturas de língua inglesa, conectando-se, portanto com o poema clássico Beowulf.

$\mathrm{Na}$ segunda parte será retratado um pouco do poema épico Beowulf, sobre o qual serão elencados alguns detalhes como sua origem e sua relação com a formação de uma identidade inglesa - a partir de sua tradução do inglês antigo, advindo do escandinavo além da produção de um pequeno resumo sobre o que se trata o poema épico.

$\mathrm{Na}$ terceira e quarta parte serão analisados o nosso suporte teórico. Dentre eles temos as considerações de Lawrence Venuti (2002 [1998]) acerca do papel da tradução e como as identidades culturais são formadas. Os conceitos propostos de Itamar Even-Zohar (2010), a respeito de como a cultura pode ser compreendida como um bem e como uma ferramenta, além da compreensão da literatura dentro do polissistema. Também será abordado por nós alguns artigos de relevância nos campos de tradução e didática da literatura inglesa em faculdades e universidades.

Com isso, tentaremos mostrar como Beowulf pode ser usado para difundir a literatura medieval e como a tradução feita por Tolkien exerce um papel fundamental.

\section{Tolkien}

J.R.R Tolkien - pseudônimo de John Ronald Reuel Tolkien - foi um escritor, filólogo e professor universitário cuja fama como escritor está associada a obras como $O$ Hobbit e a trilogia $O$ Senhor dos Anéis. Nascido no dia 3 de janeiro de 1892, em Bloemfontein, no Estado Livre de Orange (hoje parte da África do Sul), J.R.R. Tolkien passou parte da infância na África do Sul até a morte de seu pai em 1896, ano em que se mudou com sua mãe e seu irmão para a cidade de Birmingham, na Inglaterra.

Frazão (2018) relata que, "em 1908, Tolkien ingressou no Exeter College, da Universidade de Oxford e logo mostrou interesse pela filologia e por antigas sagas e lendas 
nórdicas”. Já Lopes (2006) afirma que, embora fosse aluno do curso de literatura clássica, Tolkien "desinteressou-se da área e passou a gastar muito mais tempo com estudos de filologia, sob orientação de Joseph Wright, um dos principais pesquisadores britânicos da área na época e dono de um conhecimento enciclopédico sobre o tronco lingüístico indo europeu". Segundo ele:

Tolkien descobriu o gótico, o galês e o finlandês, todos idiomas que teriam profunda influência sobre sua criação lingüística - nessa época, já esboçava algumas das línguas ficcionais que teriam papel importante no universo da Terramédia. Acabou decidindo transferir-se para a Honour School of English Language and Literature, na qual seu desempenho acadêmico melhorou substancialmente, impulsionado por seu interesse pela filologia germânica (LOPES, 2006, p. 25).

Anos mais tarde, em 1916, Tolkien serviu como segundo-tenente durante a Primeira Guerra Mundial, até contrair febris quintana (doença transmitida por piolhos, também conhecida por febre das trincheiras) e retornar à Inglaterra. Depois de sua convalescência, no âmbito acadêmico ele chegou a integrar a equipe que concluía o Oxford English dictionary, e posteriormente foi aceito como professor do Departamento de Inglês da Universidade de Leeds, para onde se mudou em 1920. Em 1925, contudo, ele foi eleito para a Cátedra Rawlinson e Bosworth de Anglo-Saxão na Universidade de Oxford, onde passaria o resto de sua vida profissional lecionando língua e literatura anglo-saxônica.

No âmbito pessoal, os anos entre e pós-guerras abrangeram boa parte das obras literárias imaginadas e escritas por Tolkien. Destacam-se as publicações de $O$ Hobbit em 1937, que serviu como ponto de partida para a trilogia de $O$ Senhor dos Anéis (1954-1955), dividida em três volumes: A Sociedade dos Anel, lançado em 1954 juntamente com As Duas Torres e $O$ Retorno do Rei lançado em 1955. Situadas na fantasiosa Terra-média, tais obras apresentam ao público uma variedade de criaturas adaptadas das mitologias que Tolkien estudou ao longo de sua vida, como os hobbits, seres pacatos e sensatos; os elfos; os humanos; os magos e os malévolos orcs e Uruk-hais.

No que tange a inspiração de Tolkien para desenvolver seu próprio legendarium Frazão (2018) argumenta que "depois de publicar os ensaios Sir Gawain e o Cavaleiro Verde (1925) e Beowulf (1936), iniciou a criação de um personagem mitológico inspirado em uma saga épica medieval, repleta de elementos fantásticos e de seres e mundos imaginários".

Embora os escritos de J.R.R Tolkien forneçam substrato suficiente para inúmeras análises, este trabalho se ocupará apenas da versão feita pelo autor de Beowulf, considerado por Medeiros (2006) como "um marco nos estudos de Beowulf, ao valorizar o poema como um todo, principalmente em relação ao seu significado e valor". Para Medeiros (2006):

Tolkien destaca a condição humana e a relaciona com elementos artísticos como “equilíbrio entre início e fim", o contraste entre juventude e velhice, com os monstros personificando as forças do mal e do caos e colocados no centro da narrativa de forma apropriada. Com este seu trabalho, Tolkien trouxe uma nova luz sobre o poema salvando-o da tradição de literatos e historiadores que apenas "dissecavam-no", analisando a obra como partes ao invés de ver Beowulf como um todo, e não como uma mera fantasia folclórica ou relato histórico. A inovação na abordagem de Tolkien foi justamente pela análise do poema em sua unidade e por sua verdadeira natureza: uma obra artística poética (MEDEIROS, 2006, p. 12). 


\section{Beowulf}

Para De Magalhães (2008), supõe-se que Beowulf "tenha sido registrado na forma escrita pela primeira vez, entre 680 d.C. e 725 d.C., na Nortúmbria, reino pertencente a região hoje conhecida como Inglaterra. No entanto, sua origem, ainda como composição oral, remonta ao repertório dos povos que habitaram o norte da Europa". Trata-se de um poema de grande extensão, escrito em hexâmetros e cujo conteúdo é basicamente mitológico. Além de tais características - associadas ao gênero épico - De Magalhães (2008) ainda aponta que:

Beowulf apresenta várias semelhanças com outros poemas de temática heróica e se encaixa na definição de épica anglo-saxã proposta por Roger Fowler. Segundo o autor, as obras pertencentes a tal gênero se caracterizam por apresentar, entre outros aspectos, os seguintes pontos: valores específicos de conduta militar, presença de material histórico, elementos mitológicos comuns aos povos germânicos antigos e preceitos do cristianismo (DE MAGALHÃES, 2008, p. 1).

Embora tenha sido escrito na Inglaterra, o poema mescla os eventos míticos protagonizados pelo herói homônimo Beowulf, cuja jornada se inicia com sua travessia pelo mar na direção do que conhecemos hoje como Dinamarca, com acontecimentos

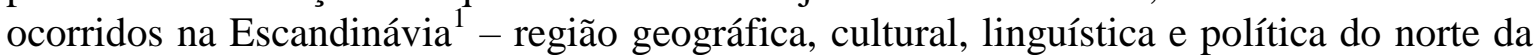
Europa - como a morte do rei Hygelac na Frísia em 521 d.C. e as guerras entre os suecos e os getas, habitantes do sul da Suécia. Em linhas gerais, Bulfinch (2014) explana que "em sua infância, Beowulf deu provas de grande força e coragem, que o levaram, depois de adulto, a libertar Hrothgar, Rei da Dinamarca, do monstro Grendel e, mais tarde, seu próprio reino do feroz dragão que lhe infligiu um ferimento mortal".

No poema, durante doze anos o rei Hrothgar sofreu com destruições provocadas em seu país por um monstro chamado Grendel que, sendo encantado, não podia ser morto por uma arma construída pelo homem. Tal monstro vivia nas terras desertas e, certa noite, saiu e atacou o palácio de Hrothgar, aprisionando e matando vários dos convidados no castelo. Sabendo disso, Beowulf seguiu, junto com quatorze marinheiros, até a Dinamarca, disposto a matar o monstro.

Ao chegar, foram acolhidos pelo rei e, à noite, prepararam uma armadilha para Grendel, que ao chegar, atacou e matou um dos marinheiros, mas este antes de morrer, conseguiu arrancar um dos braços do monstro que, ao sair para sua caverna, deixou um rastro de sangue. A mãe do monstro voltou ao castelo para vingar morte do filho e, quando retornou à caverna, foi seguida por Beowulf que, nadando, entrou e a matou. Vendo o corpo de Grendel na caverna, Beowulf cortou-lhe a cabeça e levou-a ao rei, para comprovação da morte do monstro.

Ante esse feito, Beowulf foi acolhido como herói no palácio e em sua terra natal, onde recebeu honrarias e muitos bens. Conforme explica Bulfinch (2014), "tendo-lhe sido oferecida a coroa de seu país natal, Beowulf, então muito jovem, recusou-a, em favor de Heardred, filho da rainha, ainda criança, de quem se tornou guardião e conselheiro, até que ele pudesse governar sozinho".

Porém, com a morte do rei menino Heardred na guerra contra os suecos, Beowulf o sucedeu no trono e reinou em paz por cinqüenta anos, até que um dragão começou a devastar seu reino. Já idoso, Beowulf decidiu matar este monstro tal como fez com Grendel, mas durante a batalha, foi ferido mortalmente e só conseguiu matar o dragão com a ajuda de Wiglaf, o único soldado que ficou ao seu lado até o final da luta, e se tornou seu sucessor no trono.

De Oliveira (2009) argumenta que: 
O interesse despertado pela história de um príncipe escandinavo se deve ao fato de que os escandinavos/bálticos, segundo ligação que o próprio poema faz, são ascendentes das linhagens reais dos anglo-saxões antes de sua chegada às ilhas britânicas (NILES, 1998; RAMALHO, 2007). Além disso, o poema foi composto num momento histórico de definição da existência e identidade da Inglaterra, de desenvolvimento de uma nacionalidade britânica (DE OLIVEIRA, 2009, p.1).

Com relação à definição de uma identidade da Inglaterra, é possível afirmar que, a partir do momento em que Beowulf transpôs as barreiras entre sua narração em línguas escandinavas para o inglês antigo e entre oralidade e passou a ser registrado em palavras escritas, o poema se tornou um elemento identitário das origens inglesas, uma vez que as tradições por trás do poema provavelmente chegaram à Inglaterra numa época em que os anglo-saxões ainda mantinham estreitos contatos dinásticos e pessoais com seus parentes germânicos na Escandinávia e no norte da Alemanha.

\section{Tradução, Identidades culturais e a cultura como ferramenta}

Para Venuti (2002 [1998]), o efeito de maior importância oriundo do processo tradutório é a formação de identidades culturais, que cria padrões ou cânones adaptados aos valores da língua alvo, peculiares a uma determinada época, diferentes daqueles habituais na língua estrangeira. Segundo ele:

\footnotetext{
Sem dúvida, o efeito que produz as maiores conseqüências - e, portanto, a maior fonte potencial de escândalo - é a formação de identidades culturais. A tradução exerce um poder enorme na construção de representações de culturas estrangeiras. A seleção de textos estrangeiros e o desenvolvimento de estratégias de tradução podem estabelecer cânones particularmente domésticos para literaturas estrangeiras, cânones que se amoldam a valores estéticos domésticos (VENUTI, 2002 [1998], p. 130).
}

Nos casos em que há domesticação, nota-se que os textos estrangeiros são, em geral, reescritos para se moldarem a estilos e temas que prevalecem em determinado período das literaturas domésticas, em detrimento de discursos tradutórios mais caracterizados pela historicidade, que recuperam estilos e temas do passado, inserindo-se nas tradições domésticas.

Assim sendo, seria possível afirmar que a escolha de um texto estrangeiro e da estratégia para traduzi-lo pode alterar ou alicerçar cânones literários, paradigmas conceituais, metodologias de pesquisa, técnicas e práticas comerciais na cultura doméstica. Ou seja, atrelando identidades culturais à tradução, observa-se que a mesma pode agregar respeito pela diferença cultural ou suscitar indignidade a grupos étnicos raciais e nacionais específicos.

Por isso que a tradução feita por J.R.R. Tolkien se torna não apenas uma simples identidade cultural para aqueles familiarizados com literatura medieval, mas também terá uma influência e uma propagação ao redor do mundo, levando a leitores de outras culturas o conhecimento de épico clássico da cultura anglo-saxã. Quando Venuti (2002, p.130) fala que "a tradução exerce um poder enorme na construção de representações de culturas estrangeiras", percebemos que o trabalho produzido por Tolkien consegue executar perfeitamente essa função. Pois, além de carregar o nome de um grande autor reconhecido por suas obras, a tradução do poema também se diferencia por ter sido traduzida em formato de prosa e por facilitar a leitura para leitores que estão mais acostumados com textos em prosa e que não gostam de ler poemas. 
Além disso, obras de Tolkien como $O$ Senhor dos Anéis e $O$ Hobbit foram inspiradas no poema Beowulf, dessa forma, ao trabalharmos com a tradução feita por ele, cria-se no seu leitor uma relação de familiaridade com sua escrita, ou conforme diz Venuti (2002, p.148), "a tradução forma sujeitos domésticos por possibilitar um processo de 'espelhamento' ou auto-reconhecimento". Trata-se, portanto, de um processo de compreensão e até mesmo de apreciação de leitura mais confortável.

Todavia, pode-se evidenciar que, para os leitores do século vinte, como diz Zesmer (1967) no capítulo Beowulf and the heroic tradition, a leitura e a compreensão de Beowulf foi uma tarefa difícil, para tentar decifrar os segredos contidos nela, por esta obra pertencer a uma era de obscuridades e conflitos de crenças entre os pensamentos Cristãos e crenças pagãs, os leitores atuais terão uma dificuldade ainda maior. Em suas palavras, "para os leitores do século XX, boa parte de Beowulf permanecerá obscura, por ser uma tarefa realmente difícil a de desvendar os segredos de uma era tão remota no tempo e tão diferente na organização" (ZESMER, 1967, p. 41, tradução nossa) ${ }^{2}$.

Pensando na modificação de linguagem escrita feita por Tolkien, percebe-se que, apesar de receber críticas, principalmente de acadêmicos que prezam por uma preservação da estética original da obra, pela sua versão em prosa do poema, Tolkien conseguiu manter elementos e temas cruciais e de extrema importância para a compreensão do poema.

No capítulo Beowulf and the Heroic tradition, Zesmer inicia a parte III falando que Beowulf não foi um fenômeno literário isolado, mas que possuiu elementos históricos e lendários cruciais das crenças pagãs germânicas além de ter conseguido dialogar com a visão cristã do mundo:

Beowulf is not an isolated literary phenomenon, for perhaps the most striking element in the mature art of the poem is the way in which its author took historical and legendary materials from the Germanic past, materials pagan in origin and outlook, and, using the poetic form and style inherited from this past, transmuted them into a unified epic that gave effective expression to a Christian view of the universe (ZESMER, 1967, p. 24)

Mesmo que a forma poética seja considerada um marco de criação da figura responsável pela transposição de Beowulf da oralidade para o texto escrito, ressalta-se que Tolkien conseguiu, por intermédio da prosa, demonstrar a importância que este poema possui. E tal postura adotada por Tolkien, de escolher uma forma diferente de linguagem escrita para registrar sua tradução, pode ser entendida como uma identidade cultural específica que inovou a produção de um poema épico ao se tornar mais uma maneira de propagar essa literatura pelo mundo. Utiliza-se das palavras de Lawrence Venuti para mostrar que uma identidade cultural pode trazer uma "resistência cultural", uma inovação e mudança em um determinado momento histórico.

[...] a tradução forma identidades culturais específicas e as mantém com um relativo grau de coerência e homogeneidade, mas também o modo como ela cria possibilidades para a resistência cultural, a inovação e a mudança em qualquer que seja o momento histórico (VENUTI, 2002, p. 132-133).

Sendo assim, a tradução de Beowulf feita por Tolkien seria uma escolha mais produtiva para estudar, ensinar e expandir a cultura e a literatura medieval da GrãBretanha.

Com isso, ficou claro que, ao fazer uso dessa tradução como uma ferramenta de disseminação da literatura e da cultura da Grã-Bretanha, ela se torna uma 'cultura como ferramenta'. Conceito este proposto por Itamar Even-Zohar em sua obra Papers in culture 
research de 2010, no capítulo intitulado Culture as Goods, Culture as Tools. Even-Zohar (2010) explana que a cultura sendo entendida como ferramenta é aquela que possui um determinado uso, um propósito, por um grupo ou indivíduo de uma sociedade para poder difundir e propagar um conteúdo - no caso específico da tradução de Tolkien, a literatura de inglês antigo - pelo mundo. Isso acontece pois a tradução feita por Tolkien tem um determinado uso e um objetivo proposto: a propagação de uma literatura muito importante para a construção da cultura anglo-saxã.

Nesse capítulo do livro, Even-Zohar (2010) também trabalha o conceito de cultura como um bem. Deve-se entender que essa cultura irá receber algum valor dado por um grupo ou um indivíduo na sociedade. Ou seja, no caso da análise deste trabalho, Beowulf possui um valor grandioso para não só a literatura e as lendas dos grandes heróis épicos, mas também para a cultura anglo-saxã. Como Zesmer (1967) diz: "Beowulf é o maior produto literário da civilização anglo-saxã, um poema de beleza e força incontestáveis"( tradução nossa) $)^{3}$.

Portanto, para Even-Zohar (2010), tratar a cultura como bens e como ferramentas seria:

\footnotetext{
$\mathrm{Na}$ concepção de 'cultura-como-bens', a cultura é considerada como um conjunto e estoque de bens avaliáveis, cuja posse significa riqueza, status elevado e prestígio [...] Na concepção de 'cultura-como-ferramentas', a cultura é considerado como um conjunto de ferramentas operacionais para a organização da vida, nos níveis coletivo e individual" (EVEN-ZOHAR, 2010, p. 9, 12, tradução nossa). ${ }^{4}$
}

Percebeu-se, por fim, como esse valor de bem e de ferramenta do poema épico é importante para a dispersão da literatura de inglês antigo e na sua formação de uma identidade cultural. Percebeu-se também, tomando por base os argumentos já apresentados, que Beowulf é uma das melhores produções literárias da civilização anglo-saxã, carregando em si características e traços de crenças pagãs, além da ideia de um herói épico.

\section{Ressignificações no Polissistema}

Para Even-Zohar (1997), as obras literárias não são agrupadas em conjuntos, mas sim em sistemas. Tal organização do pensamento literário implicaria em três consequências principais: os aspectos hierárquico, flexível e dinâmico dos polissistemas, assim chamados por serem sempre histórica e culturalmente localizados.

A hierarquia, nesse caso, seria advinda da posição relativa dos textos literários, estando alguns próximos ao centro do polissistema e outros, em sua periferia. Essas não seriam, no entanto, posições perenes. A cada nova adição ao sistema, os elementos anteriores se reorganizariam, em uma característica de dinamismo. O último elemento, flexibilidade, dialoga com nosso estudo, pois sistemas correlatos dialogam entre si, e um mesmo elemento pode pertencer a ambos, como é o caso de Beowulf e os sistemas histórico e literário.

Em nosso caso, a tradução de Tolkien é o elemento novo que trouxe dinamismo ao polissistema e aproximando Beowulf do centro do polissistema, além de ter restabelecido as regras da flexibilidade ao aumentar a relevância literária da obra, em detrimento da histórica.

Tais fatores são particularmente interessantes se levarmos em conta que Tolkien jamais publicou a tradução aqui estudada. Ela foi completada e engavetada em 1926, tendo sido publicada postumamente por seu filho Christopher, 88 anos mais tarde. 
O impacto dessa publicação teve três consequências principais para o polissistema literário, as quais dialogam com os aspectos de identidade cultural e bens simbólicos: a revisão histórico-literária da obra, a releitura dos textos de Tolkien acerca do texto-fonte e a discussão do papel de Tolkien enquanto tradutor e escritor.

Primeiramente, o papel inegável do tradutor na construção de universos mitológicos certamente teve influência na receptividade da obra. O sintoma mais visível desse impacto é na cronologia: desde a publicação póstuma da tradução, Beowulf tem sido listado frequentemente como um poema do século VIII, enquanto a maioria dos historiadores e filólogos conclui que a data seria posterior àquela avaliada por Tolkien.

A publicação também levou a uma revisão do ensaio "The Monsters and The Critics", baseado em uma palestra de Tolkien de 1936 em que o autor argumenta, entre outros pontos, a grandeza literária de Beowulf - a qual excederia seu valor histórico -, bem como o fato de que a narrativa não seria um épico em seu sentido estrito. Tal leitura, previamente reservada somente a estudiosos de literatura medieval, passou a ser revisitada, tanto para fundamentar a interpretação do poema, quanto para fundamentar a polêmica estrutura em prosa escolhida pelo tradutor.

Controvérsias à parte, é inegável que tal processo ajudou a estabelecer Beowulf como ferramenta cultural, sistematizando seu papel na construção contemporânea de uma identidade cultural e literária para a Grã-Bretanha.

Um último ponto a ser tratado é exatamente a voz (ou ausência de voz) do tradutor. Tolkien manifestou em correspondências seu desejo de que a tradução fosse mantida engavetada. Não tinha gosto por ela ou reconhecia sua relevância literária. $\mathrm{O}$ fato de sua perspectiva não ter sido respeitada, tendo sido agraciada com elegantes edições comemorativas, reforça o valor gravitacional de sua presença no polissistema. Tal como o toque de Midas, sua assinatura revela o poder de aproximar textos do centro do sistema, ainda que essa não tenha sido sua intenção.

\section{Considerações Finais}

Finda a análise, este trabalho concluiu que a tradução de Tolkien influencia na dispersão da literatura em inglês antigo nos dias atuais, pois ele consegue, com a sua tradução, proporcionar ao seu leitor um sentimento de familiaridade com o texto, uma vez que Tolkien, ao escrever suas principais obras teve como inspiração o poema Beowulf.

Sendo assim, leitores da literatura fantástica de Tolkien em busca de algo a mais produzido por ele encontram Beowulf e passam a ter contato com um outro tipo de literatura, disseminando, assim, para mais pessoas um pouco da cultura e literatura de língua antiga.

Além disso, Tolkien também consegue valorizar o poema como singular em seu valor e significado. Proporcionando uma nova perspectiva de escrita e de leitura de textos épicos e clássicos, pois sua forma de prosa tem um alcance na população de jovens nos dias atuais mais impactante e mais 'interessante' do que um texto em forma de poema.

Portanto, constatou-se que obras de ficção, como Beowulf, podem ser usadas para difundir as literaturas medievais, pois se aproximando mais do centro do polissistema, a tradução de Tolkien torna a obra mais relevante historicamente. O que a torna um marco na produção literária anglo-saxã, pois conseguiu retratar e relacionar fenômenos e crenças pagãs com as visões cristãs, em sua forma de prosa.

Sendo assim, Beowulf não só se torna, como é, um bem cultural, por receber uma valorização - o poema é de extrema importância para o entendimento do herói épico e da cultura da época - de indivíduos e/ou grupo, bem no qual é/e se torna uma ferramenta 
quando tem como foco o uso para a dispersão da literatura de inglês antigo, formando assim uma identidade cultural e literária da sociedade anglo-saxã.

\title{
The two eyes of the dragon: the impact of J.R.R Tolkien's translation of Beowulf in the Literary Polysystem
}

\begin{abstract}
This paper will seek to discuss how Tolkien's translation might have influenced the dispersion of Old English literature nowadays and also how works of fiction such as Beowulf can be used as introductory texts for academic students who are specializing in English literature. In order to achieve the proposed objective, this paper will use as theoretical support the cultural considerations of Lawrence Venuti (2002 [1998]) - regarding the formation of cultural identities - and of Itamar Even-Zohar (2010) - with the theory of culture as goods and culture as tools, and the Polysystem Theory -, in addition to articles of relevance in the fields of translation and didactics of English literature in colleges and Universities.
\end{abstract}

Key-words: Tolkien; english literature; translation; didactics; learning teaching process.

\footnotetext{
* Professora efetiva da Universidade Federal de Juiz de Fora nos campos de língua inglesa, tradução e estudos literários. Doutorado em Letras - área de concentração Estudos Literários, pela UFJF.

** Bacharela em Letras Tradução Inglês/Português pela Universidade Federal de Juiz de Fora (2017).

*** Mestranda em Letras: Estudos Literários da Universidade Federal de Juiz de Fora.

${ }^{1}$ Geograficamente, o termo Escandinávia refere-se à península escandinava, localizada entre o Mar do Norte e o Golfo de Bótnia e o Mar Báltico, constituindo a maior península na Europa, estendendo-se acima do Círculo Polar Ártico em 66,5 ${ }^{\circ} \mathrm{N}$ de latitude. Do ponto de vista geopolítico, o termo é equivalente a países nórdicos: Dinamarca, Noruega e Suécia, e por extensão Ilhas Faroe, Finlândia, Groenlândia e Ilhas Åland.

2 "to the twentieth-century reader much of Beowulf will remain obscure, for it is indeed a difficult task to uncover the secrets of an age so remote in time and so different in orientation"

3 "Beowulf is the greatest literary product of Anglo-Saxon civilization, a poem of incontestable beauty and strength"

4 "In the "culture-as-goods" conception, culture is considered as a set and stock of evaluable goods, the possession of which signifies wealth, high status, and prestige [...] In the "culture-as-tools" conception, culture is considered as a set of operating tools for the organization of life, on both the collective and individual levels"
}

\section{REFERÊNCIAS}

BULFINCH, Thomas. O livro de ouro da mitologia: histórias de deuses e heróis. Trad. David Jardim Júnior. Rio de Janeiro: Agir Editora, 2014.

DE MAGALHÃES, Leopoldo Doray. Beowulf, a épica anglo-saxã e o tema do cantor. Língua, Literatura e Ensino, Campinas, v. 3, p. 289-299, mai., 2008.

DE OLIVEIRA, Aline; MROGINISKI ZANESCO, Liane. Beowulf: a poesia anglo-saxônica como fonte de instrução moralizante. In: X Salão de Iniciação Científica da PUCRS, 2009, Porto Alegre. Anais. [S.1.]: EdiPUCRS, 2009. p. 3142-3143. Disponível em: <http://www.pucrs.br/edipucrs/XSalaoIC/Linguistica/Letras/70431-ALINE_DE_OLIVEIRA.pdf $>$. Acesso em: 2 nov. 2018.

FRAZÃO, Dilva. Biografia de J. R. R. Tolkien. 2018. Disponível em: <https://www.ebiografia.com/t_r_r_tolkien/>. Acesso em: 1 nov. 2018. 
EVEN-ZOHAR, I. Culture as goods, culture as tools. Papers in Culture Research. Tel Aviv: Unit of Culture Research, Tel Aviv University, p. 9-14, 2010.

Polysystem studies. Poetics Today. Tel Aviv: Unit of Culture Research, Tel Aviv University, p. 9-26, 1997.

LOPES, Reinaldo José. A árvore das estórias: uma proposta de tradução para Tree and Leaf, de J. R. R. Tolkien. 2006. Dissertação (Mestrado em Estudos Linguísticos e Literários em Inglês) Faculdade de Filosofia, Letras e Ciências Humanas, Universidade de São Paulo, São Paulo, 2006. Disponível em: <http://www.teses.usp.br/teses/disponiveis/8/8147/tde-10082007-154453/ptbr.php> Acesso em: 1 nov. 2018.

MEDEIROS, Elton Oliveira Souza de. O rei, o guerreiro e o herói: Beowulf e sua representação no mundo germânico. 2006. Dissertação (Mestrado em História Social) - Faculdade de Filosofia, Letras e Ciências Humanas, University of São Paulo, São Paulo, 2006. Disponível em: <http://www.teses.usp.br/teses/disponiveis/8/8138/tde-05072007-115753/pt-br.php>. Acesso em: 1 nov. 2018.

SANTIAGO, Emerson. Escandinávia. Disponível em: <https://www.infoescola.com/geografia/escandinavia/>. Acesso em: 1 nov. 2018.

TOLKIEN, J.R.R. Beowulf - Uma Tradução Comentada. Tradução: Ronald Eduard Kyrmse. 1. ed. São Paulo: WMF MARTINS FONTES, 2015. 544 p.

VENUTI, Lawrence. Escândalos da tradução. Trad. Laureano Pelegrin et al. Bauru: EDUSC, 2002 [1998].

NEW WORLD. New world encyclopedia. Disponível em: <http://www.newworldencyclopedia.org/entry/Beowulf\#Language_and_verse-form>. Acesso em: 1 nov. 2018.

ZESMER, David M. Guide to English literature from Beowulf through Chaucer and medieval drama. New York: Barnes \& Noble, 1967.

Enviado em: 